\title{
On the Process of Building Knowledge to Support the Design of Digital Tools: A Case Study for Future Residential Buildings on Campus
}

\author{
Pedro Soza \\ Georgia Institute of Technology \\ psoza@gatech.edu \\ Matthew Swarts \\ Georgia Institute of Technology \\ matthew.swarts@coa.gatech.edu
}

\author{
Paula Gómez \\ Georgia Institute of Technology \\ paulagomez@gatech.edu \\ Jonathan Shaw \\ Georgia Institute of Technology \\ jonathan.shaw@coa.gatech.ed
}

\begin{abstract}
This article presents the process of building knowledge to inform the process of developing a design application for mid-size urban settings. We call such an application Campus Information Modeling - CIM. Four different strategies are exposed, with special interest in a behavioral study regarding users' qualitative evaluation of buildings they inhabit and how such information will be used in the design of the CIM tool. Finally, implications and future research are discussed.
\end{abstract}

Keywords: Campus Information Model; Building knowledge; Behavioral Study; Software Design.

\section{Introduction}

Digital tools such as geographic information systems (GIS) and building information model (BIM) support both, planning and design activities at regional and building levels respectively. decision makers when forecasting new facilities and intervening existing ones at scales such as campuses and small neighborhoods. In addition, current GIS and BIM tools offer limited real time evaluation for budgetary and financial simulations, operational costs, and user accommodation. Moreover, to the best of our knowledge GIS and BIM tools does not include among their tools and functions capability to include spatial qualitative data. These three issues can be addressed under one single core question that, we think, is aligned with the main theme this conference possess; How do we build knowledge for design?

In order to address such a question we present here our work, currently under development and based on a real case in a large university in the US. The housing department of the university is increasing the number of beds they offer, and at the same time seeking to improve the environment they provide for students. In short, they seek more beds and better buildings. Consequently, the goal of this project is to build an application with capabilities to evaluate in real time different scenarios at campus scale comparing different types of residential buildings. We call this application Campus Information Modeling (CIM). Campus Information Modeling (CIM) converges all sources of spatial, financial, and users' data about buildings, structures, and land into a common information intermediate scale framework. However, before delving deep into CIM model issues, we envision a key question that emerge prior the development of such a tool: What

kind of information does such a system need, and which are the most reliable sources to obtain that data?

To address this question we designed a strategy to gather different types of reliable data that may be used for real time evaluation of design options. Thus, four approaches for data acquirement were used in the design of the strategy for capturing data: First, we complete a revision of the existing buildings in campus. Second, we review the financial model regarding construction and operation budgets in residential buildings in campus. Third, we did a literature review of current issues in college housing. Fourth, we ran a behavioral study with students living in campus. These four steps provide the set of data that became the inputs to develop the model of the CIM tool. Using as case study the renovation of residential buildings for undergrad students that will take place during the next academic year we offer here the methodological approach designed to build and embed knowledge on such tool.

\section{Analysis of Existing Building Layouts and Room Arrangement:}

To obtain an overview of the types of buildings, room arrangements, and characteristics of locations that the Housing Department offers to students living in campus we complete a revision of the 45 buildings used as residential settings. The revision included a descriptive classification of buildings into categories according to type of footprint and layout, type of room arrangement, number and type of units per building, common spaces, and number of stories. We also collected gross square footage, location, and demographic information about residents 


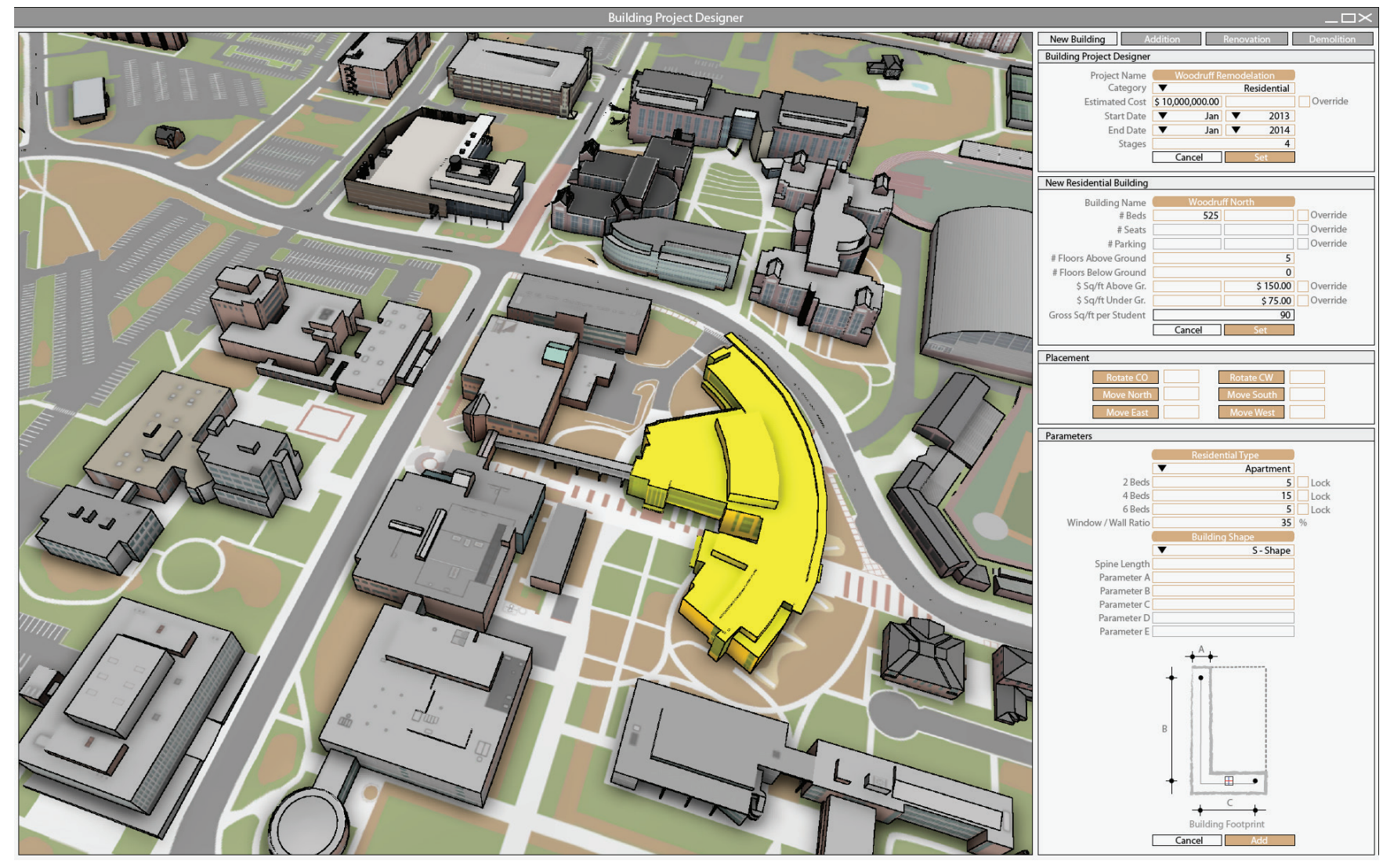

Figure 1: Screenshot of designer module and examples of building foot-print layouts, dropdown menus, and design tools. The basic parameters defined were project type, building layout, room arrangement, placement options, budget, schedule, and square footage.

living in campus. With this set of information we extracted relationships and metrics regarding students' population and types of residence halls such as square footage per student according to their level (freshmen, sophomore, junior, senior, and graduate), number of students living in traditional dormitories, suites and apartments. Those metrics were used to formulate design constraints and equations regarding proposals of square footage per student as well as different options of footprint layouts and room arrangement. Furthermore, based on square footage per students, we implement restrictions and design options in the CIM tool regarding square footage of common spaces, housing staff requirements, leisure spaces, exteriors, and service areas. Finally, the most important consideration that emerged from this part of the project was that students and square footage of architectural program were the basic units of analysis, and inputs, for the CIM tool.

\section{Informed Model Regarding Budgetary and Financial Considerations:}

Data gathered about the financial model used by the housing department, which was provided by the housing director for budget and finance was incorporated into the CIM tool's model. Thus, student rotation throughout the school year, percentage of occupancy, and renovations and operational cost were added into the CIM model. Furthermore, energy consumption, insurance cost, carrying charges, personnel, project management, and utilities emerged as new factors that were also pre-defined as equations into the CIM model. These set of equations provide real time estimation of operational cost, energy consumption, and utilities according to the number of students or the square footage estimated by the design proposal.

Consequently, financial issues were added as the third main source of information, along with number of students and square footage of architectural program in the model of the CIM tool. However, questions arose during this stage of work. Why do students rotate? Why do they move out of campus? What can we do to diminish rotation? Is there anything we can do, as designers and architects, to provide better buildings and such an environment in which students would like to stay until the end of their programs? What are the qualitative issues we are missing in our model? Can we, for instance and in order to provide a better environment, capture and embed qualitative information about space in the CIM tool?

With the intention of explore possible answers to these new questions, we made an extensive literature review of housing issues and its implications for students' satisfaction and academic performance. The main assumption behind the new point of view was, and still is, that a real time evaluation tool for the campus information modeling should go beyond just the number of 


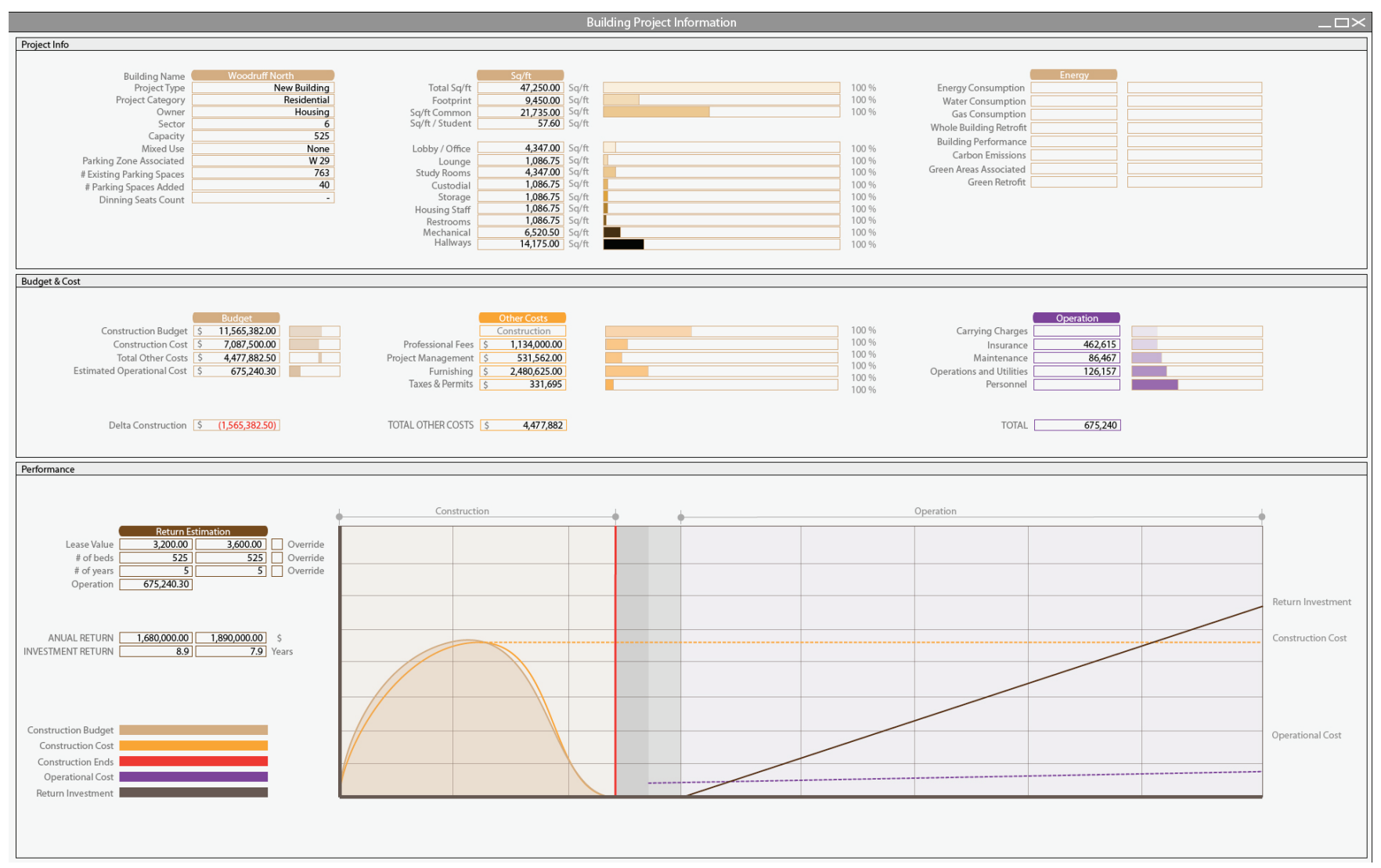

Figure 2: Screenshot of the real time feedback evaluation module.

students, square footage, and budgetary issues. We should also incorporate satisfaction, efficiency, and effectiveness into the set of equations driving the simulation and evaluation of scenarios for analysis and comparison.

\section{Literature Review of Housing Issues:}

We reviewed key studies regarding issues in residential hall design and its correlations with post occupancy building's evaluation, occupancy rates, and operational matters. As results of the revision we notice two main streams; studies reporting variables used to make design decisions in housing projects (new buildings and renovation of existing ones), and studies reporting variables used to assess building occupancy and performance. Hence, on one hand we found that financial issues, sustainability, location regarding dinning and parking facilities, and proposal of common spaces are the most common factors used to make design decisions in residence halls design. Furthermore, the key finding from the design decision making point of view was that common spaces are usually proposed to enrich students' life by offering leisure, mentoring, and studying spaces (Balogh, Grimm and Hardy, 2005; Banning and Kuk, 2011; Deninger and Swift, 2009; Li, Sheely and Whalen 2005; Price 2003; Riker and Decoster 2008; Romano and Hanish 2003). On the other hand, the main issues that emerged regarding residence hall evaluations were administrative and technological issues, renovation and maintenance, special population needs, parent involvement, creation of learning communities, multicultural issues, staff issues, students' satisfaction and success, and sense of place of belonging (Amole 2009; Brandon, Hirt and Cameron, 2008; Carrol et all., 2003; Johnson and Cavins 2006; Najib, Yusof and Osman 2011; Thomsen and Eikemo 2011). As can be seen the criteria to make design decisions and post occupancy evaluations are not aligned, but actually dissimilar. We decided to tackle this dichotomy by grasping one aspect that demonstrated important weight in the literature regarding students' satisfaction and willingness to continue living in residence halls in campus: students' satisfaction. For instance, Brandon, Hirt and Cameron found that students living in traditional residence hall have more interactions than students living in suites' buildings, value living in a community, and this condition is as valuable as privacy for students (Brandon, Hirt and Cameron, 2008). Another study that introduced the concept of residential colleges claiming that mix residence halls offer an opportunity to bring major cultural shift in campus culture at the same time that promoting community living (Carrol et all., 2003). In such environments, mixed residence halls incorporate classrooms, study areas, dinning services, recreational spaces, common rooms, and very well planned exteriors. Likewise Johnson and Cavins (2006) found that faculty involvement and mixed spatial conditions are among the key factors supporting such success and decreasing students housing rotation. Najib, Yusof and Osman (2011) addressed physical and social variables and examined the level of student satisfaction with students' 


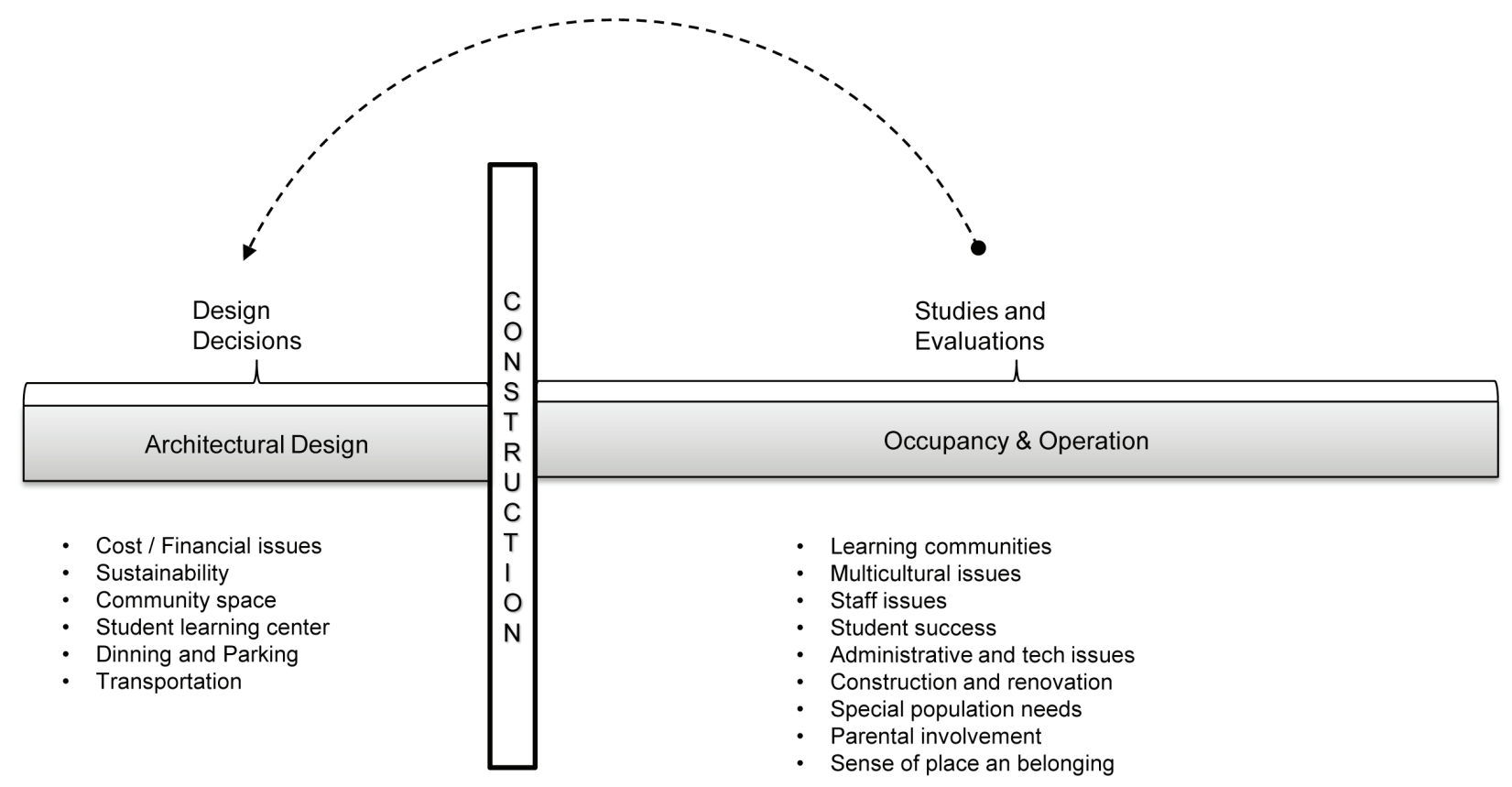

Figure 3: Criteria used for design decision-making and post occupancy evaluation according to the literature.

accommodations. Their work focuses on the level of satisfaction that students feel with housing facilities, but omits factors that influence satisfaction. Such a gap was studied by Amole who found correlations among morphological types of residence halls and students' satisfaction mediated by physical, social, and managing considerations (Amole, 2009). With these studies at hand, we defined the fourth step in the process of building knowledge for the design of our CIM tool by proposing a behavioral study to gather data regarding the institute students' level of satisfaction and their experience living in campus.

\section{Behavioral Study: Students' Satisfaction.}

In order to inform the software design, we incorporate housing users to improve the definition of parameters, options, and functionality the CIM tool will offer. The goal of this step was to gain insights and feedback about the considerations we are taking into account to develop the CIM tool, and to test such criteria with the final users, students living on campus. Thus, a new research question was done asking what kind of variable bounds together space and behavior in residence halls. Using an approach similar to Amole (2009) three dimensions; social, psychological, and environmental were defined as the key factors driving students' level of satisfaction with their residence halls. The main hypothesis states students' satisfaction rest on the positive correlation among these three dimensions. We operationalized these three dimensions in a set of variables from which students' interactions emerged as a key issue behind students' satisfaction with their hall environment since this is the variable that bounds together space and behavior. We also add type of layouts and room arrangements we found in the descriptive study at the beginning of the project as new variables to study correlations among students satisfaction with their hall and floor plan type and room arrangement. In order to perform the study and define metrics for analysis purposes, an interaction among students was defined as a casual encounter in which students chat for more than three minutes. The study was conceived as a between subject study. We ran five focus groups and five interviews to professional housing staff members to collect data. Each focus group involve the participation of 5 to 8 students in which volunteers were asked to mark on a floor plant the places where they had interactions with other students during the previous four days to the focus group. Then, the marks were transferred to a unique large floor plan, a common document, differentiating students by colors. A discussion was guided by the researches asking the students about the patterns they observed in the building occupancy during the interactions and details of specific situations, such as the level of occupancy they notice in different places or rooms during such encounters, the type and number of interactions they notice regarding specific places, properness of residence hall layouts for informal encounters, and the students' level of satisfaction with the environment provided by such residence halls. Finally, we also asked the students and professional staff members' opinion about other models of residence hall design like residence colleges reviewed in the literature review of housing issues. The conceptual model of students' satisfaction and its variables is depicted in figure 4 . 


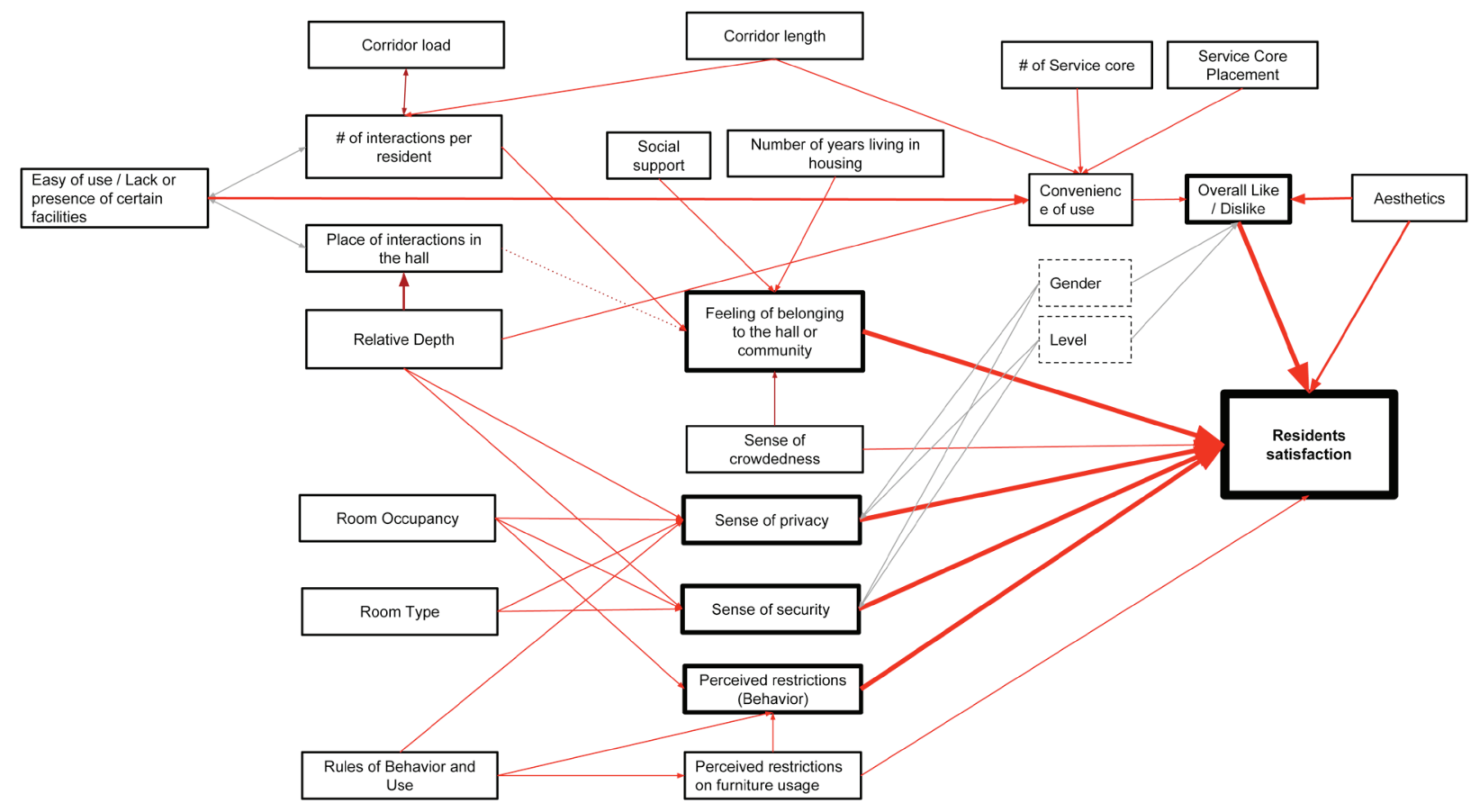

Figure 4: Model of residents' satisfaction for students living in campus.

\section{Future Work}

We envision the implementation of the findings as design constraints in the CIM tool. So far, the trends that have emerged as key issues in this study are students' level of interactions on common spaces in residence halls, and level of satisfaction with different types of room arrangement. According to the literature, both issues impact students' satisfaction, willingness to continue living in campus, and even students' performance. Thus, we envision that predefined options regarding such variables can be used as predefined design constraints in the CIM tool. We plan to use such constraints to display real time feedback regarding the level of satisfaction that the students will most likely experience for each design option the CIM tool will offer. Tied to such constraints, we envision capability to predict building performance in terms of rotation rates, students' satisfaction with the program and layout, and types of room arrangement the future building will offer. With our work, still under development, we hope to contribute at current discussion regarding how we generate and use knowledge for developing digital design tools.

\section{Acknowledgments}

We thanks to the Spatial and Innovation Group, The Digital Building Lab, Capital Planning and Space Management Office, and the Housing Department at The Georgia Institute of Technology for their support and help with this project. We also thanks Professor Sonit Bafna for his contribution to define the behavioral study included in section number 4 of this paper.

\section{References}

Amole, D., (2009). Residential satisfaction in students housing in Nigeria. Journal of Environmental Psychology, 29, 76-85.
Balogh, C., Grimm, J., \& Hardy, K., (2005). ACUHO-I Construction and Renovation Data: The latest trends in housing construction and renovation. Journal of College and University Student Housing, 33(2), 51-56.

Banning, J., \& Kuk, L., (2011). College housing dissertations: A bounded qualitative meta-study. Journal of College and University Student Housing, 37(2), 91-105.

Brandon, A., Hirt, J., \& Cameron, T., (2008). Where you live influences who you know: Differences in student based on residence hall design. Journal of College and University Student Housing, 35(2), 63-78.

Carroll, J., Carnaghi, J., Lempfert, T., \& Johnes, K. (2003). What comes first: The program or the facility?. New Directions for Students Services, $101,53-68$

Deninger, L., \& Swift, J. (2009). Integrated design: A sustainable mindset for residence halls. Journal of College and University Student Housing, 36(1), 48-70.

Johnson, W.G., \& Cavins, K. (1996). Strategies for enhancing student learning in residence halls. New Directions for Students Services, 75 69-82.

Li, Y., Sheely, M., \& Whalen, D. (2005). Contributors to residence hall student retention: Why do students choose to leave or stay?. Journal of College and University Student Housing, 33(2), 28-36.

Najib, N., Yusof, N., \& Osman, Z. (2011). Measuring satisfaction with student housing facilities. American Journal of Engineering and Applied Sciences, 4(1), 52-60.

Price, J. (2003). From first design brainstorm session to final coat of paint Communication, an essential constant. New Directions for Students Services, 101, 39-51.

Romano, C. R., \& Hanish, J. (2003). Balancing multiple needs through innovative facility design. New Directions for Students Services, 101 39-51.

Thomsen, J., \& Eikemo, T. (2010). Aspects of student housing satisfaction: A quantitative study. Journal of Housing \& the Built Environment, 25, 273-293. 